\title{
Impact of electromobility on the future standard load profile
}

\author{
Ali Hashemifarzad ${ }^{\mathrm{a}}$, Martin Faulstich ${ }^{\mathrm{b}}$, Jens zum Hingst $^{\mathrm{c}}$, Milad Jokari $^{\mathrm{d}} *$ \\ ${ }^{a}$ Institute of Electrical Power Engineering and Energy Systems, TU-Clausthal, Germany \\ ${ }^{b}$ Institute of Electrical Power Engineering and Energy Systems, TU-Clausthal, Germany \\ ${ }^{c}$ Institute of Electrical Power Engineering and Energy Systems, TU-Clausthal, Germany \\ ${ }^{d}$ Institute of Electrical Power Engineering and Energy Systems, TU-Clausthal, Germany
}

\begin{abstract}
Although Electromobility provides an appropriate technological solution to the low-carbon-emission goals of "Energiewende", it poses specific challenges in terms of the increase in the electricity demand and the integration into the grid infrastructure across Germany and eventually the whole Europe. Considering the attained strategies in Energiewende, a significant increase in the number of electric-driven vehicles in future is expected. Germany's "National Electromobility Development Plan" has set the targets to have one million electrical vehicles on the road by 2020. [2] Considering the current battery technologies and charging characteristics of electrical cars, a noteworthy impact on the distribution net-works and grids should be expected in near future.

In this paper, the impact of electric vehicle charging on the distribution grid and standard load profiles will be investigated. To achieve the mentioned objective, different charging strategies for electric cars and their effects on the electricity network will be analysed. Two scenarios, assuming respectively 50 and 88 percent market penetration of electric vehicles by 2050, will then be introduced. The current conventional standard load profiles of households and industrial units will be used to investigate the impact of electric vehicle charging on them for each development scenario.
\end{abstract}

Keywords: Electromobility, Energiewende, Standard load profile, Load forecasting

\section{Introduction}

Germany has set its goal toward attaining a low carbon, environmental friendly, reliable and affordable energy supply by the year 2050. This energy transition, or the so called "Energiewende", is not merely limited to the power sector but it goes far beyond and affects many cross-sectoral areas. The energy transition follows a transparent and step-by-step strategy toward 2050 with specific tar-gets. Consequently, the transport sector follows a long-term strategy with the aim to reduce the energy consumption by $40 \%$, referenced to the year 2008 [1]. One of the bold aims in this strategy is the immense increase in Electromobility by 2050 . The German government has in-vested around 2.2 billion in this area, hoping to become the market leader and provider in the E-mobility section by 2020 . The "Electromobility Law" of 2014 and the related policies necessitate the German federal government to achieve the mentioned goals by 2050. Considering the mentioned strategies, a significant increase in the number of electric-driven vehicles in future is expected. Germany's "National Electromobility Development plan" has set the targets to have one million electrical vehicles on the road by 2020 [2].

Battery Electric vehicles (BEVs) are nowadays rarely found on German roads. The automotive industry in Germany has already brought a few purely electric-driven models to the market in recent years.

\footnotetext{
* Manuscript received May 7, 2018; revised January 12, 2019.

Corresponding author. E-mail address: ali.hashemifarzad@tu-clausthal.de

doi: $10.12720 /$ sgce.8.2.164-173
} 
Also there are plenty of the so-called Plug-in-Hybrid models, which have both the electric and the combustion engines. However, despite the state subsidy on electric vehicles, the prices are still high and the consumers are not yet convinced to approach these vehicles. Another Obstacle in having a higher number of E-cars on the roads is the low range that an E-car can travel with a fully-charged battery. Regardless of the duplicitous advertisements, this range hardly reaches $200 \mathrm{~km}$ and it can be considered as a major drawback, unless the power stations are extended in several regions. To overcome the mentioned pitfall, the federal government of Germany has significantly invested on the expansion of the charging stations through the states of Germany by means of establishing new charging stations or increasing the capacity of the current ones. Moreover, the Government is imposing pressure on the German automotive industry by legislating and imparting new regulations and measures for $\mathrm{CO} 2$ emission, which can be only met if considerable proportions of BEVs are sold. Furthermore, the competitions with the American and Chinese electric car manufacturers prompt the German manufacturers to act and invest in this field.

All in all, in near future, there will be undoubtedly a growing number of BEVs in Germany. According to the government national development plan, every tenth car on the German roads would be purely electric driven by 2030 [2]. For this purpose, the appropriate infrastructures need to be offered. These include, the investments in power stations for BEVs, which should be available everywhere with the ability of charging the electric cars with a relatively fast process, and the electricity network needs to be developed based on the new consumers and new consumption behavior. For designing the new network infra-structures and adjusting the old network, different factors should be taken into consideration, such as the increase in electricity demand, the times of a day in which the BEVs mainly load the network, the charging time of BEVs and the difference between the private BEVs and company vehicles or public transportations. Considering the mentioned increase in the number of BEVs in future, these parameters can have a major influence on the standard load profiles (SLPs), which will be described with more details in chapter four. In this study, it is tried to investigate these effects through two different scenarios, which assume respectively 50 and 88 percent market penetration of electric vehicles by 2050 . Furthermore, the possibility of developing smart strategies for charging the BEVs will be discussed to evaluate the opportunity of compensating peaks in daily SLPs in attempt to have a smooth residential and industrial electricity load curve.

\section{BEVs Charging Technology}

There is no uniform charging concept and standards for BEVs so far and different manufacturers use different plugs for their own productions and as a result, the plugs in Europe are completely different than the ones in US or Asia.

Regarding the plug type, McKinsey (2014) argued that the Type 2 German plugs are prevailing. This model can deliver a power range of $3.7 \mathrm{~kW}$ to $43 \mathrm{~kW}$, based on the private or public usage of the charging stations. The private models are designed to be compatible with the avail-able households' infrastructure and can be connected to an ordinary household socket. But in France, for example, there are mainly type 3 plugs in charging stations, which are developed by Italy. In Asia, mainly the type 1 plugs are used, which are limited to a power transmission of up to $7.4 \mathrm{~kW} \mathrm{[3].}$

This diversity in charging plugs hinders having a universally compatible charging station model. However, the charging technology is developing constantly, an example of which can be seen in the introduction of the combined charging systems or CHAdeMO. Through These technologies, direct DC power is delivered which enables even higher charging capabilities. This allows the so-called "Quick Charging" technology which can charge the BEVs in a few minutes.

Although it does not appear to be very user-friendly, but in long term, it would be better to use only plugs, which are DC-power based, i.e. they can deliver DC power directly to cars, provided a DC converter is installed in the charging stations. Thus, it would be possible to have a considerably lower charging time. Also, having an AC-to-DC converter in cars costs significantly more in comparison to a built-in conversion unit in the charging stations, in which more place, is available. However, having such 
on-board units in the BEVs, makes the cars heavier.

Still, there will be a problem, which is totally independent of the plug technology. According to Spähn et.al (2014), a high-power charging, as described, puts a sudden pressure on the electricity network. Thus, the maximum performance may not be used in all cases, since the network is not designed to hold such sudden loads, especially in private charging stations such as houses. Therefore, quick charging is not always guaranteed [4].

\section{Integration of BEVs in Electricity Network}

\subsection{Simultaneity and the charging power}

Since the privately used BEVs are usually charged in the evening and overnight, they can influence the load profile and the peak load. Nobis et.al (2015) mentioned that the peak load of residential areas and households in 2050 are normally at 18:00; without the influence of the Electro-mobility. By the expected increase in Electromobility in near future and the living habits, many BEVs also will be charged at this time. Depending on the power delivered by the charging process, the charging duration will change and also the time of the network load could shift. With a higher charging power, the charging duration decreases, but it imposes extra load on the network. On the other hand, at a lower charging power, the process takes longer but the load on the network will be shifted toward later hours. It should be also considered that due to the shorter duration in higher power charging, the simultaneity is less frequent. The simultaneity increases the network load. However, without any regulation both types of the charg-ing processes can lead to an increase in the existing load peak, due to simultaneity. To avoid this, the charging process can be postponed to the low-electricity-consumption hours of the night, during which the network is normally relatively less loaded and the charging process might even help to have a smoother and nearly a flatter load profile for households [5].

\subsection{Flexibility of charging interval}

The escalation of Electromobility can overload the poorly developed low-voltage networks. The charging controlling systems can shift the charging process to the lower loaded times of the day or the times with a high share of PV yield. However, this shifting can also lead to high simultaneities, due to widespread charging controls, which in turn can have feedback effects on possible load peaks. Nobis and Fischhaber (2011) have calculated the necessary power for electric vehicles in 2030, which is not particularly very high and it is only $1.4 \%$ of the total German load (with $1.5 \mathrm{GW}$ annual maximum) but high enough to offer secondary services in 2030. In this study, the charging curve for two sample days of an average week in 2030 is presented [5]. (Fig. 1)

The bars show the hourly energy consumption of the BEVs. The colour marking of the bars indicates how flexible that specific portion of energy in that respective hour is to be shifted without changing the whole amount of charging energy. The dark blue in Fig. 1 indicates the portion of energy which could be shifted at least 12 hours and the red part shows the portion, which almost cannot be shifted at all. This figure shows that a large part of the charging process is flexible (with an average of 12 hours) and has a high potential for smart controlling. It is due to the charging behaviour of the users, who usually charge the vehicle after the last ride of the day and use it the next morning. Thus, by means of an intelligent charge control such as shifting the load peak to other times, the negative network effects could be significantly reduced.

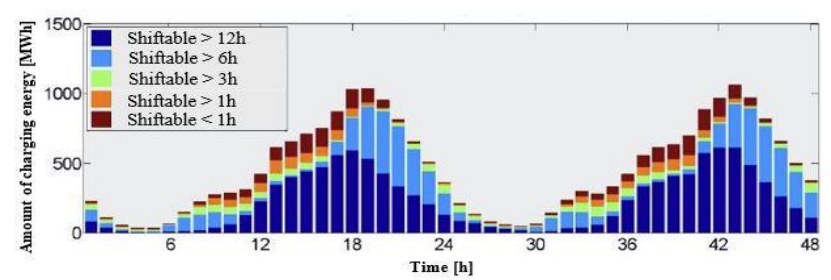

Fig. 1. Flexibility of the charging load in 2030 (two days) [5]. 
On the other hand, as a result of the fluctuation in energy supply from the renewable resources, an idea was developed, which suggested applying the batteries in BEVs as a temporary storage unit to save the excess electricity from PV modules or wind turbines. Hence the BEVs can also serve to stabilize the network. However, besides the high costs, this leads to significantly higher numbers of charging/discharging processes in network, which can also de-crease the capacity and life time of batteries.

\subsection{Smart grids}

To integrate the BEVs in electricity network, a regulation of energy supply and an intelligent distribution network is required. For this purpose, an energy management system (EMS) is required to send and receive information to/ from the electricity network to react accordingly. It also requires a measurement station and also a bidirectional charging system, which not only supplies the batteries with electricity, but also is able to feed the energy back into the electricity network.

Reiner et.al (2009) indicated that two types of energy values are needed to form the basis for network stabilising by using BEVs. The first one is the required driving energy, which shows the amount of energy that should be stored in the battery for the next ride. By analysing the driving pattern of the car, an approximate time of the start of the next ride can be predicted. Since normally enough time is available for the charging process before the next ride, the energy from BEVs can be used during this period to contribute to grid stability. However an accurate prediction of driving behaviour is not possible. Thus the system should be designed in a way that the driver can always rely on a base charged vehicle or communicate to the system in case of exceptional longer trips.

The second type is the so-called spotting energy, which describes the amount of electricity, which can be loaded to the vehicle or can be fed back to the grid if required [6].

A project at Badenova AG done by Noeren et.al (2011) in Freiburg has studied the load caused by Electromobility on the network. The target of this study is the low-voltage networks and residential areas, since these are particularly vulnerable to overloads and also it is expected to have many charging stations in such areas in future. Several scenarios have been studied and the results show that the 100\% electrification of mobility will not necessarily be without any challenges for the networks. For example, assuming a charging power of $3.5 \mathrm{~kW}$, only a quarter of the E-vehicles can be charged at the same time. However, with this power, the charging process takes longer and it is more likely that the charging power of $10 \mathrm{~kW}$ is used. In this case, only one tenth of the autos can be charged at the same time, otherwise there will be an overload on the network. Therefore, a costly expansion and regulatory measures are needed. In order to avoid such a huge expansion process or overloads on network, the charging times should be shifted into low load times by intelligent controlling systems EMS to ensure the network stability [7].

\section{Standard Load Profiles (SLPs)}

The standard load profiles (SLPs) represent the pattern of electricity usage of supply market customers. A load pro-file normally gives the Hourly pattern or 'shape' of usage across a day or the pattern across the settlement year, for the average customer of different profile classes. Based on this data, it is possible to follow the amount of sup-plied energy and the behaviour of different classes of customers. However, there is a difference between the real measured- and modelled SLPs. Since an accurate and continuous measurement of the consumption would not be feasible from an economic point of view, the consumption is calculated by measuring at specific time intervals and averaging the measured values. There are many different consumers connected to a network. The energy suppliers distinguish between different types of consumers, e.g. private households and industrial consumers. Based on these classification, the suppliers model the SLPs. Besides there are other external factors, which must be also included. Therefore there is a distinction be-tween "Weekday", "Saturday" and "Sunday", as well as the three time zones "winter time", "transition period" and "summer time" [8] [9]. 
Fig. 2 shows the SLP for a private household in Germany during winter. The three graphs represent different types of days. It can be observed that the load peak always occurs at 12:00 and 18:00 and the consumption decreases in the afternoon and in the evening and at night it reaches the lowest level. On Sundays, there is also a load peak at 8:00 in the morning.

However, the difference between these three graphs ap-pear on the amount of the load peaks, where on Satur-days the consumption at noon is the highest and on Sun-days is the lowest. Also it is obvious that in the evening the electricity consumption is higher during the week. These differences indicate the necessity of distinguishing different types of the days [10] [11].

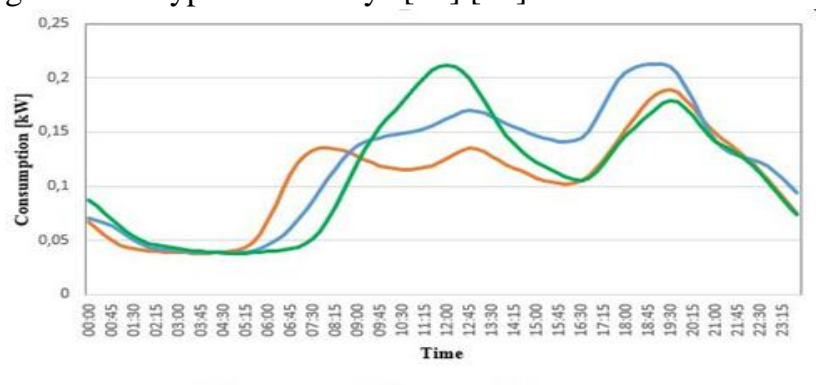

Fig. 2. Standard last profile H0 for households in Germany during winter [11]

Fig. 3 shows a comparison between electricity con-sumption in summer- and winter time for a private house-hold for a normal weekday.

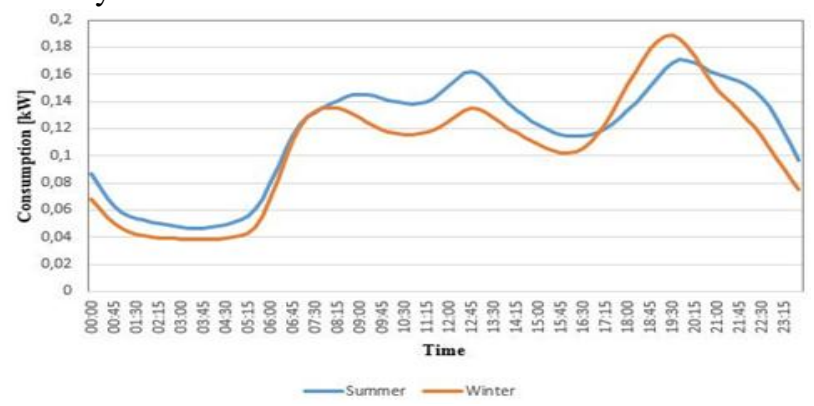

Fig. 3. Comparison between Standard last profile H0 for households during weekdays in Germany during winter and summer [11]

It can be seen that during the night and in the morning the load is less in winter. However, in the afternoon and evening, the peak load in winter is higher. This can be due to the increased use of electrical light sources in winter, when there are fewer hours of sunshine.

The same comparison was made by VEW-Bericht (2000) for an industrial consumer. (Fig. 4) In contrast to the residential consumers, this figure shows that for industrial consumers, the consumption in winter is higher than summer [11].

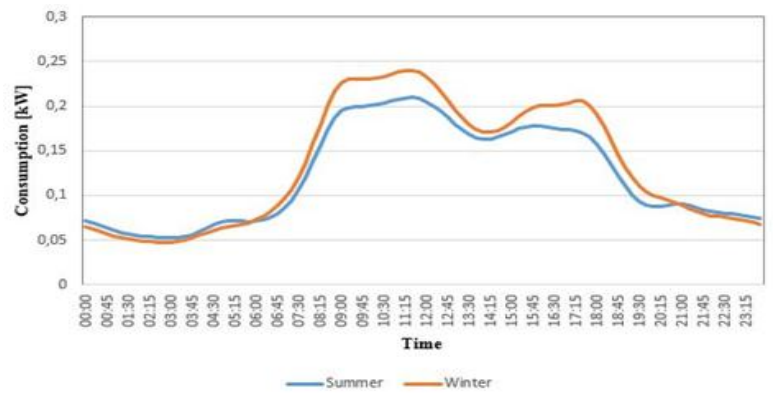

Fig. 4. Comparison between Standard last profile G0 for an industrial consumer during weekdays in Germany during winter and summer [11] 


\section{Development Scenarios}

\subsection{Electrification rate in 2050}

Today the transportation is largely provided by the vehicles powered by combustion. Following the goals of the "Energiewende" in Germany toward a low-carbon, environmentally friendly, reliable and affordable energy sup-ply by the year 2050, the transport sector must undergo a significant restructuring to achieve the targeted reduction of the energy consumption by $40 \%$ relative to 2008 . The German government has invested around 2.2 billion in this area, hoping to become the lead market and provider by 2020 . The new "Electromobility Law" in 2014 and other policies in this regard ensures the German federal government to achieve their goals by 2050 .

Faulstich et.al (2016) indicated that due to the limited potential for the cultivation of biogenic fuels and the generation of synthetic fuels resulting from high losses, an $88 \%$ conversion to electromobility is predicted till 2050. [12] As a result of the assumed electrification with a share of $88 \%$ of the road and rail transport, the total energy requirement (including fossil fuels) in this sector can be reduced by nearly 50 Percent. It will thus drop from 779 TWh (18 TWh electricity) in 2012 to 365 TWh ( 223 TWh electricity) in 2050. [13] However this is a very ambitious target and by varying the electrification rate in transportation sector, the total energy requirement will also increase. For instance, by a 50\% electrification the energy consumption will increase to about $633 \mathrm{TWh}$ in year 2050, of which almost 491 TWh is electricity [14]. (Fig. 5)

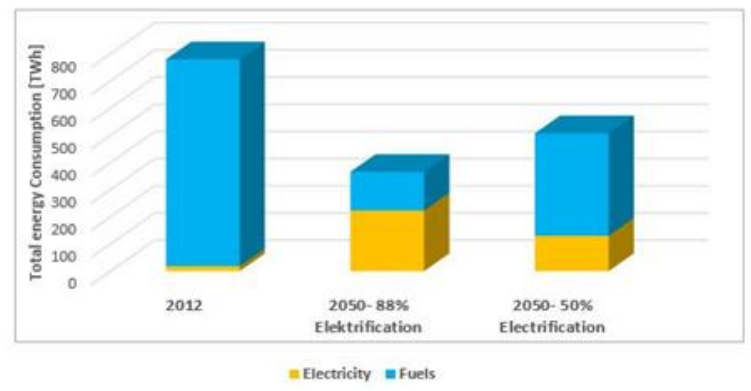

Fig. 5. Total energy consumption in 2012 and 2050 (with 88 and 50 percent electrification) [13]

\subsection{SLPs in 2050}

In this paper the following assumptions have been made to predict the residential and industrial standard load pro-files in Germany for 2050:

- The consumption behaviour of the residential sector will change and the efficiency of electrical devices will increase. Based on the studies of AGEB (2013) and BMU (2012), the energy consumption in Germany is $4.697 \mathrm{kWh}$ per per-son in 2012 and the predictions show a 6.3\% reduction till 2050. [15] [16]

- The basic load profiles are built on the assumption that people have no preference concerning recharging time; this means that recharging occurs whenever a car is parked and a charging station is available. However, here it is supposed that the vehicle will be charged via an intelligent controlling system, which can shift the recharging process.

- Stated by the European Commission (2013), for the simulation of charging and discharging profile of a small BEV, an average electricity consumption of $0.13 \mathrm{kWh} / \mathrm{km}$ is presumed. This consumption is an average rate for driving on roads with normal speed [17]. This value is also in accordance with the figures reported by RWTH (2010), which are derived from real driving cycles of a BEV showing a consumption between nearly $0.12 \mathrm{kWh} / \mathrm{km}$ (driving on roads) and nearly $0.2 \mathrm{kWh} / \mathrm{km}$ (driving on motorways or in traffic jams) [18].

- The basis for the SLPs are the assumptions that every day the BEV must at least cover a distance of 
about $40 \mathrm{~km}$, so that it has a charging requirement of about $5,2 \mathrm{kWh}$.

- It is supposed that for residential consumers the vehicle must be available from 6:00 to 22:00 on normal week days, from 9:00 to 24:00 on Saturdays and from 10:00 to 22:00 on Sundays.

- Also, it is assumed that for industrial consumers, the vehicle must be available from 6:00 to 18:00 on normal week days and on weekends the vehicle will not be used.

Based on the mentioned assumption, the charging profile of a BEV is modelled in Matlab and the optimal residential SLP for a household with an average of three people in 2050 is calculated. Figure 6 to Figure 8 show the results for a sample week day in winter in 2050. [19]

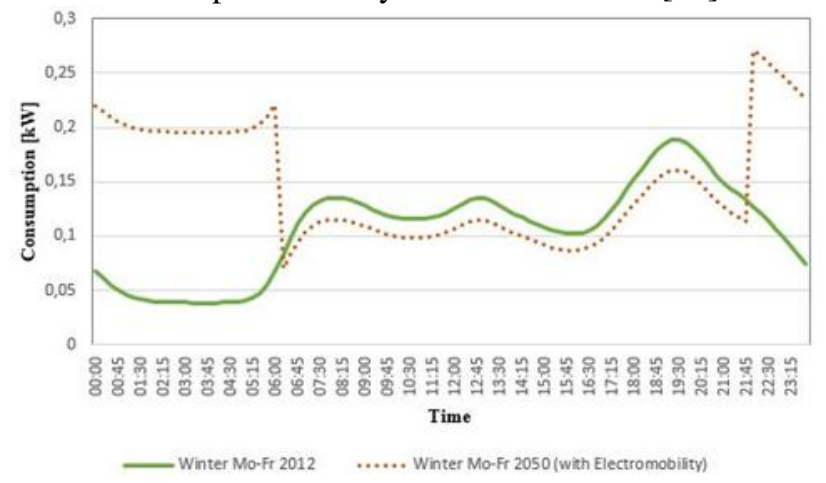

Fig. 1. Residential SLP on Mo-Fr during winter 2050, Germany

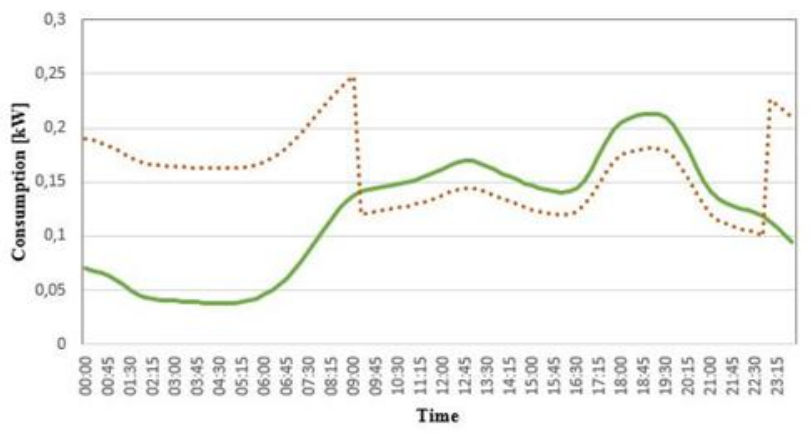

Winter Sat $2012 \quad$...... Winter Sat 2050 (with Electromobility)

Fig. 7. Residential SLP on Saturdays during winter 2050, Germany

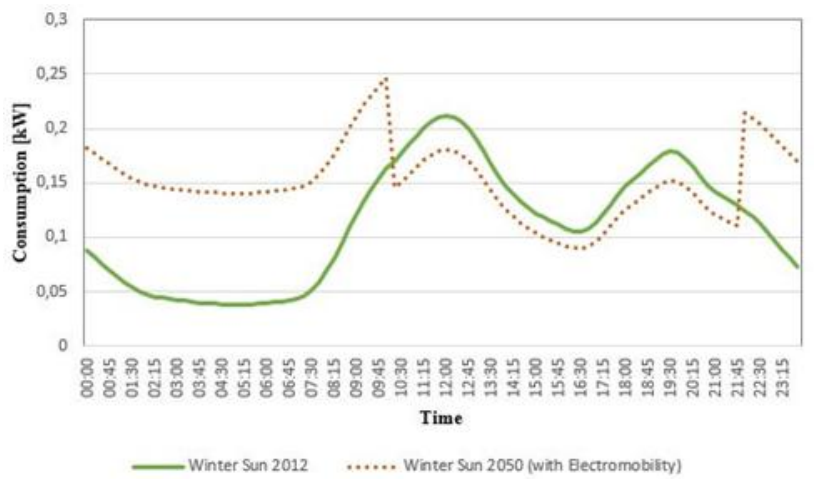

Fig. 8. Residential SLP on Sundays during winter 2050, Germany

The same process is done for an industrial consumer based on the same assumptions and the results are presented in Fig. 9 to Fig. 11. [19] 


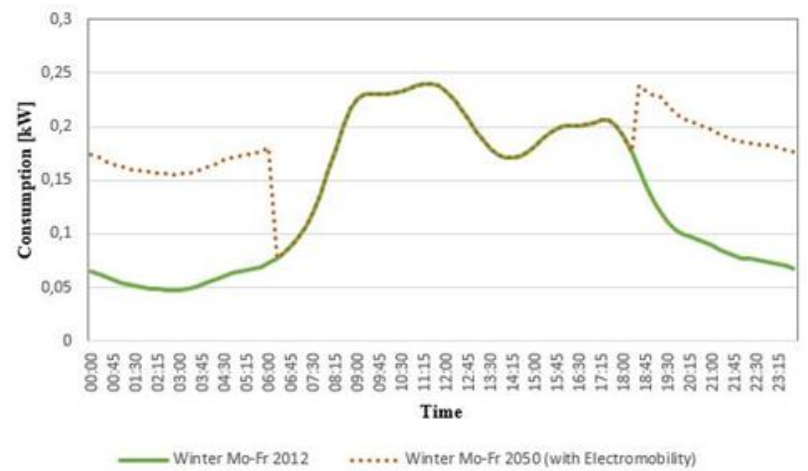

Fig. 9. Industrial SLP on Mo-Fr during winter 2050, Germany

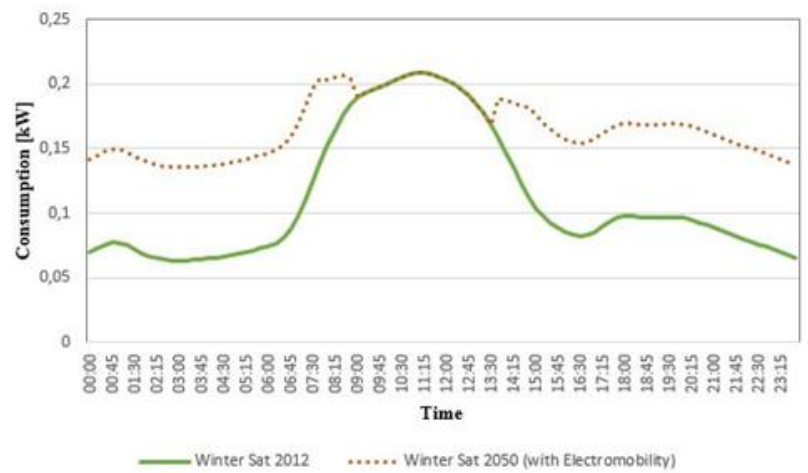

Fig. 10. Industrial SLP on Saturdays during winter 2050, Germany

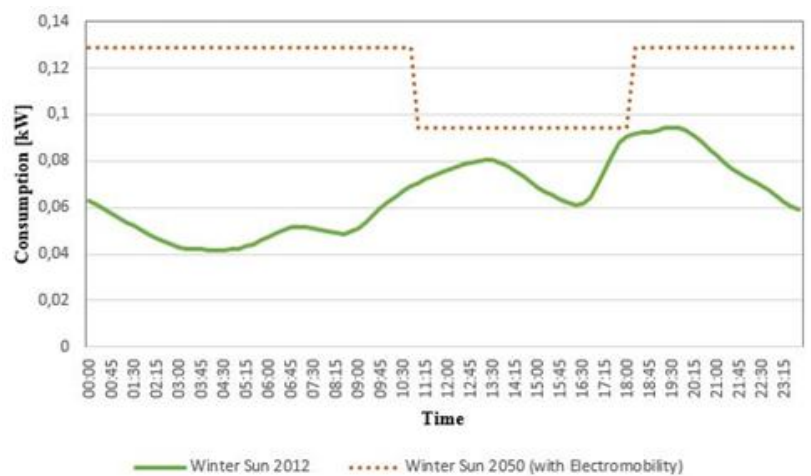

Fig. 11. Industrial SLP on Sundays winter 2050, Germany

It should be mentioned that in the simulation of the industrial SLPs, it was considered that although the $\mathrm{BEV}$ will not be used on weekends, the consumption is higher in residential sectors normally between 10:00 to 18:00. Therefore, the charging process is shifted to the lower load times of the network.

\section{Discussion}

It can be observed from Figures 6 to 8 that in year 2050, compared to year 2012 which the effect BEV's on SLP is nearly negligible, the SLP faces a significant increase from late hours of night (approximately after 22:00) until early hours of the day (6:00 during workdays and 9:00 during the weekend). Generally these hours are the best time for the residents to charge their cars while the consumption and the simultaneity probability is relatively low. The industrial SLPs nearly follow the same 
process during the week days. However during the weekends in 2050, the increase in SLPs is seen in more hours of the day. In this regard, studying a hub or charging pool to in-vestigate the influence of simultaneity on the network and SLPs, can help to have a better vision in energy management.

\section{Further Studies}

One of the ideas that the authors of this work suggest to be investigated on, is the participation of the government its related organizations such as Deutsche Bahn (DB), which can actively take part by purchasing significant amount of electric cars from the auto industries and sharing them publicly with the people for their daily uses. This should be in such a way that using them would be a better, cheaper and more reliable option instead of conventional fossil fuel burning vehicles. In this way, besides the fact that all three sides (Government, people and the industry) will benefit, more accurate observations can take place on the variations of SLP rates during different times and the effect of simultaneity of EV charging on them plus the driving patterns of the drivers in each district. Having a stronger monitoring over the parameters just mentioned can lead to a more efficient energy management system (EMS) that enables us to stabilize the net-work and prevent overloads on it. Similar to what the company BMW is doing with its DriveNow car sharing system, a system can be designed in the form of an application or a software program where the user sets its destination and the AI (artificial intelligence) decides which car would be the best for the user to choose that has enough battery to take him/her to desired destination.

In addition to that idea the developments of smart grids (SG) can also play an important role in reducing the electricity consumption and shifting the load to the hours, in which the consumption is less to have a smoother SLP.

Nowadays developed SGs have opened the way for feasibility, reliability and durability increase of power systems and their utilization have revolutionized the energy industry. One important aspect of SGs is the usage of various Energy Storage (ES) Systems, among which Electric Vehicles (EV) are considered. Electric storage systems in electric cars not only act as power consumers, but also as mobile power sources that can sell their power to the grid in times of need and increase the reliability of the grid.

In smart grids, the electricity demand market is also closely monitored along with the supply side. Consumers can reduce their costs of using energy storage utilities by applying the applications of Demand Response (DR). In that regard, for reaching the mentioned benefits, an exclusive and flexible Energy Management System (EMS) is needed which can make the best decisions at the right moment.

This system of energy management must be able to plan and act for different time phrases separately. Considering the fact that the required energy of the consumers is non-contiguous and in no period of time we have constant load, EMS can sell the surplus electrical load during peak hours to the network and buy electricity at the hours, when the load is low on the network or the electricity price is negative.

In these circumstances the presence of electric vehicles and energy storages can reduce the energy that consumers such as Home-Microgrids (H-MG) consume. Moreover H-MGs can provide the electricity that energy storage units need in the peak hours of the day. This means if in the peak hours we use energy storage systems to provide the energy demand of home-microgrids and charge them (ESs) in the rest of the day (when the load on the network is not high), we can stop more costly electricity generators from working and reduce the expenses and emitted pollutants caused by them.

\section{Conclusion}

Electromobility plays an important role in achieving the targets of "Energiewende" in Germany. The studies show an ambitious electrification rate of $88 \%$ by the year 2050 . Realizing this goal means a significant increase in electricity demand, together with many challenges regarding integration of Electromobility into the grid infrastructure across Germany and even the whole Europe, which influence the whole structure of energy systems from the supply to distribution.

This paper studies the impact of Electromobility on the standard load profiles in 2050. For this sake, at first the general charging strategies of EVBs were introduced and the flexibility of the charging process in 
terms of time shifting was discussed. The residential and industrial SLPs for 2012 were then presented and the total required electricity in 2050 was studied based on the two ambitious and less ambitious scenarios for the electrification rate till 2050. The charging profile of a standard EVB was then modelled in Matlab. Several criteria were defined to optimize the charging time of the EVB and finally the results were presented. The results show an overall increase in electricity consumption, however it can be concluded that by smart controlling of the BEVs charging process it is possible to make a critical contribution to grid stability, for instance by shifting the charging time to the lower loaded times of the network to have a smooth load curve.

In this study, the charging station was assumed to be used privately. Furthermore, the other frameworks and general conditions such as economic and population growth can affect the consumer's behaviour. A study on the changes in the consumption behaviour of industrial consumers, for instance, can help to achieve more accurate SLPs for this sector in 2050.

\section{References}

[1] Federal Ministry for Economic Affairs and Energy: Die Energiewende: unsere Erfolgsgeschichte, Berlin, January 2017

[2] The Federal Government Report: Nationaler Entwicklungsplan Elektromobilität der Bundesregierung, Berlin, August 2009

[3] Amsterdam Roundtables Foundation, McKinsey \& Company: Evolution, Electric vehicles in Europe: gearing up for a new phase, Netherlands, April 2014

[4] Spähn, Michael JA, Nauck, Enrico: Ganzheitliche Integration der Elektromobilität in das Stromnetz der Zukunft, VDEKongress 2014 - Smart Cities - Intelligente Lösungen für das Leben in der Zukunft, Frankfurt, October 2014

[5] Philipp N, Sebastian F, Forschungsstelle für Energiewirtschaft e.V. : Belastung der Stromnetze durch Elektromobilität. 2015

[6] Dipl.-Ing. Ulrich R, Prof. Dr.-Ing. Thomas Leibfried, Dipl.-Inform. Florian Allerding, Prof. Dr. Hartmut Schmeck: Potenzial rückspeisefähiger Elektrofahrzeuge und steuerbarer Verbraucher im Verteilnetz unter Verwendung eines dezentralen Energiemanagementsystems. Hg. v. KIT. 2009

[7] Dominik Noeren, Christof Wittwer: Abschlussbericht (Kurzfassung) Effiziente Mobilität (EFFMOB). Hg. V. Fraunhofer ISE, Freiburg, 2009 - 2011

[8] Deutsches Kupferinstitut (Hg.) (2017): Lastprofile. Online available under https://www.kupferinstitut.de/de/werkstoffe/anwendung/eenergie/energiewende/lastprofile.html, last checked on 13.05.2017

[9] Forschungszentrum Jülich (Hg.): Standardlastprofil. Online available under https://enargus.fit.fraunhofer.de/pub/bscw.cgi/d63235262/*/*/Standardlastprofil.html?op=Wiki.getwiki\&amp;search=once\%2 0through\%20steam\%20generator, last checked on 14.05.2017

[10] Alexander Probst, Martin Braun, Stefan Tenbohlen, Erstellung und Simulation probabilistischer Lastmodelle von Haus-halten und Elektrofahrzeugen zur Spannungsbandanalyse Probabilistic load modeling and simulation for households and electric vehicles for voltage band analysis, Uni Stuttgart, 2016

[11] Verband der Ernährungswirtschaft e.V, VDEW-Bericht: Lastprofilverfahren zur Belieferung und Abrechnung von Kleinkunden in Deutschland, January 2000

[12] CUTEC: Faulstich, M.; Beck, H.-P.; Haaren, C. von; Kuck, M.; u.a.: Szenarien zur Energieversorgung in Niedersachsen im Jahr 2050. Hannover: 2016

[13] Federal Agency for Nature Conservation: Naturverträgliche Energieversorgung aus $100 \%$ erneuerbaren Energien 2050. von Haaren, C., Walter, A., Wiehe, J., Schlömer, G., zum Hingst, J., Hashemifarzad, A., Albert, I., Hofmann, L., von Haaren, C. Bonn: 2018

[14] CUTEC (2016a): Faulstich, M.; Beck, H-P.; Brendel, R.; Hanke-Rauschenbach, R.; u.a.: Szenarien zur Energieversorgung in Niedersachsen im Jahr 2050. Zusatzgutachten zeitlich höher aufgelöste Szenarien. Hannover: 2016

[15] AGEB - ARBEITSGEMEINSCHAFT ENERGIEBILANZEN e. V. : "Anwendungsbilanzen für die Energiesektoren in Deutschland in den Jahren 2011 und 2012 mit Zeitreihen von 2008 bis 2012", November 2013

[16] Federal Ministry for Environment, Nature Conservation and Nuclear Safety BMU (Hrg.), DLR, Fraunhofer IWES, IFNE: "Langfristszenarien und Strategien für den Ausbau der erneuerbaren Energien in Deutschland bei Berücksichtigung der Entwicklung in Europa und global" (Leitstudie 2011 - Schlussbericht an das BMU). 2012

[17] European Commission, DG JRC, Institute for Energy and Transport, Petten, the Netherlands: Projections for Electric Vehicle Load Profiles in Europe Based on Travel Survey Data, Italy, 2013

[18] RWTH.: Parameter manual. Deliverable of WP 3.1 of G4V, Project co-funded by European Commission 7th RTD Programme, 2010

[19] Fischer, L. Seminar Project, Institute of Power and Electricla Engineering, TU-Clausthal. 2017 